\title{
Structure, expression differentiation and evolution of duplicated fiber developmental genes in Gossypium barbadense and G. hirsutum
}

\author{
Huayu Zhu, Xiaoyong Han, Junhong Lv, Liang Zhao, Xiaoyang Xu, Tianzhen Zhang, Wangzhen Guo*
}

\begin{abstract}
Background: Both Gossypium hirsutum and G. barbadense probably originated from a common ancestor, but they have very different agronomic and fiber quality characters. Here we selected 17 fiber development-related genes to study their structures, tree topologies, chromosomal location and expression patterns to better understand the interspecific divergence of fiber development genes in the two cultivated tetraploid species.

Results: The sequence and structure of $70.59 \%$ genes were conserved with the same exon length and numbers in different species, while $29.41 \%$ genes showed diversity. There were 15 genes showing independent evolution between the A- and D-subgenomes after polyploid formation, while two evolved via different degrees of colonization. Chromosomal location showed that 22 duplicate genes were located in which at least one fiber quality QTL was detected. The molecular evolutionary rates suggested that the D-subgenome of the allotetraploid underwent rapid evolutionary differentiation, and selection had acted at the tetraploid level. Expression profiles at fiber initiation and early elongation showed that the transcripts levels of most genes were higher in Hai7124 than in TM-1. During the primary-secondary transition period, expression of most genes peaked earlier in TM-1 than in Hai7124. Homeolog expression profile showed that A-subgenome, or the combination of A- and D-subgenomes, played critical roles in fiber quality divergence of G. hirsutum and G. barbadense. However, the expression of D-subgenome alone also played an important role.
\end{abstract}

Conclusion: Integrating analysis of the structure and expression to fiber development genes, suggests selective breeding for certain desirable fiber qualities played an important role in divergence of G. hirsutum and G. barbadense.

\section{Background}

Cotton (Gossypium spp.) is the world's most important fiber crop plant. While most of the $>50$ Gossypium species are diploid $(n=13)$, five are allopolyploids $(n=26)$, originating from an interspecific hybridization event between A- and D-genome diploid species. Humans have independently domesticated four different species for their fiber, two of which are diploids, Gossypium herbaceum and G. arboreum, and two are allopolyploids, G. hirsutum and G. barbadense [1].

Alhough G. hirsutum and G. barbadense probably originated from a single hybridization event between

\footnotetext{
* Correspondence: moelab@njau.edu.cn

National Key Laboratory of Crop Genetics \& Germplasm Enhancement, Cotton Research Institute, Nanjing Agricultural University, Nanjing 210095, China
}

\section{Biomed Central}

A- and D- diploid species, the two have very different agronomic and fiber quality characteristics. The high yield potential and diverse environmental and production system adaptability of G. hirsutum make it the most widely cultivated species, accounting for about $97 \%$ of the world's cotton fiber [2]. G. barbadense is a more modern species possessing superior fiber quality. Novel alleles are responsible for the improved fiber quality in G. barbadense. Despite its higher fiber quality, however, the narrow adaptation range and low yield of G. barbadense limit its cultivation. The two Gossypium species are sexually compatible, although partial sterility, longer maturity, and hybrid breakdown are often observed in later generations [3]. Nonetheless, the introgression of favorable alleles from G. barbadense to G. hirsutum would likely improve the fiber quality of 
G. hirsutum while simultaneously maintaining its high fiber yield [4].

The cotton fiber is a single cell without the complex cell division and multicellular development that develops from ovule's epidermal cells. Fiber development occurs in four distinct, but overlapping stages: initiation, elongation, secondary wall synthesis, and maturation [5]. To date, many of the genes predominantly expressed in cotton fiber development have been isolated and characterized. Gh14-3-3L was found to be predominantly expressed during early fiber development, and may be involved in regulating fiber elongation [6]. Yoder et al. [7] defined pectate lyase (PEL) as a cell wall modification enzyme. GhPel was found to play an essential role in fiber cell elongation by degradation of the deesterified pectin for cell wall loosening [8]. Ruan et al. [9] suggested the sucrose synthase gene (Sus) played an important role in the initiation and elongation of singlecelled fibers by influencing carbon partitioning to cellulose synthesis. GhBG ( $\beta$-1,4-glucosidase), one of three cellulases, was specifically expressed in fiber cells and plays an important role in degradation of the primary cell wall and promotion of secondary cell wall synthesis [10]. Cotton CelA1 and CelA2 genes, encoding the catalytic subunit of cellulose synthase, are expressed at high levels during active secondary wall cellulose synthesis in developing cotton fibers [11]. Two cotton Rac genes, GhRacA and $G h R a c B$, expressed in the fibers at the initiation and elongation stages, might play an important role in early fiber development [12]. In addition, several genes are expressed specifically or preferentially in fibers [13-18], although their exact functional roles remain unclear.

In theory, there are two homologs in tetraploid cotton species, representing descendants from the A-genome and D-genome donors at the time of polyploidy formation. The goals of this study were to: 1) better understand the genetic basis of cotton fiber development, 2) identify the structural difference of duplicated genes, and 3) reveal the expression and evolution of fiber quality differences between upland and sea-island cotton. To complete this study, we selected 17 fiber development genes accessioned in National Center for Biotechnology Information (NCBI, http://www.ncbi.nlm.nih.gov) to study structure and expression differences of the two cultivated tetraploid species. To investigate their frame and sequence divergence, we initially cloned these genes in the genome DNA of the G. hirsutum accession TM1, the G. barbadense cultivar Hai7124, and their two putative diploid progenitors. The chromosomal locations of each homeolog of several studied genes, having effective single nucleotide polymorphism (SNP) or amplification polymorphism loci between TM-1 and Hai7124 were determined by linkage analysis in allotetraploid cotton using an interspecific $\mathrm{BC}_{1}$ mapping population (TM-1×Hai7124) $\times$ TM-1] [19-22]. Finally, expression patterns of each gene and each homeolog were explored. A more thorough understanding of interspecific divergence of cotton will provide a solid foundation from which key fiber quality genes may be exploited in cotton molecular breeding.

\section{Results}

\section{Sequence and structure analysis of fiber development genes}

The orthologs of each of the 17 genes were cloned and sequenced (GenBank accession numbers (GQ340731GQ340736, HQ142989-HQ143048, and HQ143055HQ143090; Table 1). Phylogenetic groupings and sequence comparisons allowed the copy number for all genes, except Exp1 in the Hai7124 cultivar, to be independently isolated with a single copy from the diploid species and two homeologs from each tetraploid species for each gene. There was a single copy of Exp1 in the diploid species and two distinct copies in TM-1, however, the Exp1 sequence from Hai7124 was of only one type, though more than 10 clones were selected randomly to sequence. This result was further validated by a different primer pair of this gene (see Additional file 1: Supplemental Table S1 for list of primer pairs). The sequence from Hai7124 has a closer relationship with G. raimondii than with $G$. herbaceum. Further, southern blotting of Exp1 performed on the four species, showed two distinct hybridizing bands after digestion with EcoRI and HindI in Hai7124 and TM-1, and one hybridizing band in G. herbaceum and G. raimondii (Figure not shown), which indicated that Exp1 had two copies in both TM-1 and Hai7124. Combining sequence and southern blot analysis, the homeolog of Exp1 in the A-subgenome of Hai7124 was colonized to a type resembling that of the D-subgenome via nonreciprocal homoeologous exchange [23].

The lengths of the genomic DNA sequences isolated from the four species varied from $1020 \mathrm{bp}(\operatorname{Exp} 1)$ to 6126 bp (CelA3) (Table 2). Based on the alignments between the genomic DNA and the cDNA sequences in orthologs, twelve genes (70.59\%) shared the same intron/exon structures in different genomes, and variations in length were mainly caused by insertion/deletion events within introns (Additional file 2: Supplemental Figure S1A). The remaining five genes (29.41\%), CIPK1, CAP, BG, ManA2 and CelA3, produced some structure differences caused by different exon length or numbers (Additional file 2: Supplemental Figure S1B).

Seventeen gene trees were constructed using the NJ method to distinguish the duplicated genes independent of evolution or local interlocus recombination after tetraploid formation. Two major clades, one including 
Table 1 Names and characteristics of fiber development-related genes

\begin{tabular}{|c|c|c|}
\hline Gene & $\begin{array}{l}\text { Accession } \\
\text { code }\end{array}$ & Potential function \\
\hline $\begin{array}{l}14-3- \\
3 L\end{array}$ & DQ402076 & 14-3-3-like, may participate in the regulation of fiber elongation. \\
\hline CAP & AB014884 & adenylyl cyclase associated protein, may play a functional role during early stages of cotton fiber development. \\
\hline CEL & AY574906 & endo-1,4-beta-glucanase, necessary for plant cellulose biosynthesis. \\
\hline CelA1 & GHU58283 & cellulose synthase \\
\hline CelA3 & AF150630 & cellulose synthase catalytic subunit \\
\hline CIPK1 & EF363689 & calcineurin B-like (CBL) protein-interacting protein kinases, was highly expressed in the elongating phase in developing fiber \\
\hline Exp 1 & DQ204495 & alpha-expansin 1. \\
\hline Exp & DQ060250 & $\begin{array}{l}\text { Expansin, directly modify the mechanical properties of cell walls, enable turgor-driven cell extension, and likely affect length } \\
\text { and quality of cotton fibers. }\end{array}$ \\
\hline ACT1 & AY305723 & actin1, plays a major role in fiber elongation. \\
\hline$B G$ & DQ103699 & $\begin{array}{l}\beta-1,4-\text { glucanase, plays an important role in the loosing of the primary cell wall and in the promotion of secondary cell wall } \\
\text { synthesis. }\end{array}$ \\
\hline ManA2 & AY187062 & beta-mannosidase, glycosyl hydrolase \\
\hline Pel & DQ073046 & $\begin{array}{l}\text { pectate lyase, exclusively degrade the de-esterified pectin, may play an important role in the process of normal fiber } \\
\text { elongation in cotton. }\end{array}$ \\
\hline POD2 & AY074794 & bacterial-induced peroxidase \\
\hline RacA & DQ667981 & small GTPase gene, might play an important role in the early stage of fiber development. \\
\hline RacB & DQ315791 & small GTPase gene, might play an important role in the early stage of fiber development. \\
\hline Sus1 & U73588 & $\begin{array}{l}\text { sucrose synthase, play an important role in the initiation and elongation of cotton fiber by influencing carbon partitioning } \\
\text { to cellulose synthesis. }\end{array}$ \\
\hline LTP3 & AF228333 & Lipid transfer protein gene, involved in cutin synthesis during the fiber primary cell wall synthesis stage \\
\hline
\end{tabular}

G. herbaceum and the A-subgenomes of TM-1 and Hai7124, the other including G. raimondii and the D-subgenomes of TM-1 and Hai7124, were formed for 15 genes (Additional file 3: Supplemental Figure S2A). High bootstrap values supported duplicated genes independent of evolution after tetraploid formation. Two genes were determined to have local interlocus recombination or colonization after tetraploid formation (Additional file 3: Supplemental Figure S2B). ACT1 from G. raimondii was more closely related to $A C T 1 s$ from G. herbaceum and the A-subgenomes than with ACT1s from the D-subgenomes. This relationship suggests that

Table 2 Structure analysis for orthologs of fiber development genes in four cotton species

\begin{tabular}{|c|c|c|}
\hline Gene & Numbers of exon & Length of ORF(bp)/numbers of derived amino acids \\
\hline $14-3-3 L$ & 7 & $762 / 253$ \\
\hline CAP & $A_{1}$, Ath and Atb: $10 ; D_{5}$, Dth and Dtb: 9 & $\mathrm{~A}_{1}$, Ath and Atb: $1416 / 471 ; \mathrm{D}_{5}$, Dth and Dtb: $1338 / 445$ \\
\hline CEL & 6 & $1860 / 619$ \\
\hline CIPK1 & 1 & $A_{1}$, Ath and Atb: $1341 / 446 ; D_{5}$, Dth and Dtb: $1347 / 448$ \\
\hline$B G$ & Dth: 7; Dtb: 8; $A_{1}, D_{5}$, Ath and Atb: 9 & Dth: 1050/349; Dth: $1365 / 454 ; A_{1}, D_{5}$, Ath and Atb: 1884/627 \\
\hline Exp1 & 3 & $777 / 258$ \\
\hline Exp & 3 & $780 / 259$ \\
\hline POD2 & 3 & $984 / 327$ \\
\hline RacA & 8 & $636 / 211$ \\
\hline$R a c B$ & 7 & $588 / 195$ \\
\hline Sus1 & 12 & $2418 / 805$ \\
\hline Pel & 3 & $1236 / 411$ \\
\hline ManA2 & Ath: 11; Atb: 9; $A_{1}, D_{5}$, Dth and Dtb: 11 & Ath: 2925/974; Atb: 1380/459; A $1, D_{5}$, Dth and Dtb: 2931/976 \\
\hline CelA1 & 12 & $2925 / 974$ \\
\hline CelA3 & Ath and Atb: 8; $A_{1}, D_{5}$, Dth and Dtb: 14 & Ath and Atb: 2055/684; $A_{1}, D_{5}$, Dth and Dtb: 3204/1067 \\
\hline ACT1 & 4 & $1134 / 377$ \\
\hline LTP3 & 1 & $363 / 120$ \\
\hline
\end{tabular}

$\mathrm{A}_{1}=$ G. herbaceum L. var. africanum, $\mathrm{D}_{5}=\mathrm{G}$. raimondii Ulbr, Ath = A subgenome of G. hirsutum L. acc. TM-1, Dth = D subgenome of G. hirsutum L. acc. TM-1, $\mathrm{Atb}=\mathrm{A}$ subgenome of G. barbadense L. cv. 7124, Dtb = D subgenome of G. barbadense L. cv. 7124. 
ACT1s from the $\mathrm{D}$-subgenomes evolved at an accelerated rate, relative to $A C T 1 s$ from the A-subgenomes. The Exp1 sequence in Hai7124 was closer to that found in G. raimondii.

To locate all 17 homeolog gene pairs on our backbone genetic map [23], the subgenome-specific PCR primers (Additional file 4: Supplemental Table S2) and singlenucleotide amplified polymorphisms (SNAP) primers (Additional file 5: Supplemental Table S3) were used to detect polymorphisms between TM-1 and Hai7124. Polymorphic primer pairs were also used to survey 138 individuals of the $([(\mathrm{TM}-1 \times$ Hai7124 $) \times \mathrm{TM}-1]) \mathrm{BC}_{1}$ mapping population (Table 3 ). Eight gene pairs were located on their corresponding homeologous chromosomes, and each of six pairs were located on one of their homeologous chromosomes, while three pair of genes, Exp, Exp1 and CelA1 could not be mapped because no available polymorphic loci were found between TM-1 and Hai7124. A large body of data was compiled by integrating previously reported cotton fiber quality quantitative trait locus (QTL) [24-34] with the 22 identified fiber quality-related genes within $20 \mathrm{cM}$. Most genes had at least one fiber quality QTL; some had several (Table 3), indicating important fiber quality roles.

\section{Rates of sequence evolution}

With only a few exceptions, purifying selection, as indicated by $\mathrm{Ka} / \mathrm{Ks}<1$, appears to be in place for most of pairwise comparisons (Table 4). The exceptions include $G$. herbaceum ( $\mathrm{A}_{1}$ genome, $\mathrm{A}_{1}$ ) vs G. hirsutum $\mathrm{A}$-subgenome (Ath) of POD2 and $\mathrm{D}_{5}$ vs Dth of RacA, which demonstrated positive selection $(\mathrm{Ka} / \mathrm{Ks}>1)$, as well as $D_{5}$ vs Dtb of RacA, $\mathrm{A}_{1}$ vs Atb of 14-3-3L, $\mathrm{A}_{1}$ vs Ath and $\mathrm{A}_{1}$ vs Atb of $C A P$, which had exceptionally strong positive selection $(\mathrm{Ka} / \mathrm{Ks}>1)$.

Because there were no nucleotide substitutions in $A_{1}$ vs Atb of RacA, $\mathrm{A}_{1}$ vs Atb of EXP, $\mathrm{D}_{5}$ vs Dth and $\mathrm{D}_{5}$ vs Dtb of LTP3, and all RacBs pairs, it was not possible to compare their evolutionary rates. Although those particular "not applicable" comparisons (NA vs NA) were

Table 3 Integration analysis of chromosomal locations of genes and fiber quality QTL reported in other studies

\begin{tabular}{|c|c|c|c|}
\hline Gene & Subgenome & Chromosomal location & QTL associated with specific chromosome \\
\hline \multirow[t]{2}{*}{ 14-3-3L } & At & A5 & $F E^{h} ; F^{d,}{ }^{d, j} ; F_{F}{ }^{d, g}, i, j, F S^{d}$ \\
\hline & Dt & D5 & $F F^{i} ; F^{j} ; F^{j} L^{j} ; F^{g}$ \\
\hline \multirow[t]{2}{*}{ CAP } & At & A13 & - \\
\hline & Dt & D13 & $\mathrm{FL}^{\mathrm{b}, \mathrm{g}} ; \mathrm{FS}^{\mathrm{g}}$ \\
\hline \multirow[t]{2}{*}{ CEL } & At & - & - \\
\hline & Dt & D6 & $F L^{d, h, j} ; F F^{h, i, j, k} ; F E^{k} ; F S^{d}$ \\
\hline \multirow[t]{2}{*}{ CIPK1 } & At & - & - \\
\hline & Dt & D7 & $\mathrm{FS}^{\mathrm{f}}$ \\
\hline \multirow[t]{2}{*}{$B G$} & At & A13 & - \\
\hline & Dt & D13 & - \\
\hline \multirow[t]{2}{*}{ POD2 } & At & $\mathrm{A3}$ & $F E^{b}, j ; F F^{b} ; F S^{b, h} ; F L^{h}$ \\
\hline & Dt & D2 & $\mathrm{FE}^{\mathrm{j}}$ \\
\hline \multirow[t]{2}{*}{ RacA } & At & A12 & $F L^{l, e, j} ; F^{\prime} ; F^{g}$ \\
\hline & Dt & D12 & $\mathrm{FS}^{\mathrm{e}} ; \mathrm{FL}^{\mathrm{d}}$ \\
\hline \multirow[t]{2}{*}{$\operatorname{RacB}$} & At & A5 & - \\
\hline & Dt & D5 & $\mathrm{FF}^{\mathrm{i}} ; \mathrm{FU}^{\mathrm{i} ;} ; \mathrm{FL}^{\mathrm{j}} ; \mathrm{FE}^{\mathrm{g}}$ \\
\hline \multirow[t]{2}{*}{ Pel } & At & A3 & $F E^{b j} ; F F^{b, d} ; F S^{b, h} ; F^{h, d} ; F E^{j}$ \\
\hline & Dt & - & - \\
\hline \multirow[t]{2}{*}{ ManA2 } & At & A13 & - \\
\hline & Dt & D13 & $F L^{b, g, h} ; F E^{h} ; F S^{d, g} ; F F^{d} ; F U^{d}$ \\
\hline \multirow[t]{2}{*}{ CelA3 } & At & A8 & $\mathrm{FS}^{\mathrm{h}} ; \mathrm{FE}^{\mathrm{h}}$ \\
\hline & Dt & D8 & $\mathrm{FF}^{\mathrm{g}, \mathrm{j}} ; \mathrm{FS}^{\mathrm{j}} ; \mathrm{FE}^{\mathrm{j}}$ \\
\hline \multirow[t]{2}{*}{ Sus1 } & At & A5 & $F E^{h} ; F L^{d, i, j} ; F F^{d, g, i, j, j} ; F^{d}$ \\
\hline & Dt & - & - \\
\hline \multirow[t]{2}{*}{ LTP3 } & At & A10 & 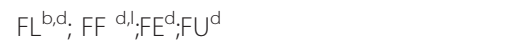 \\
\hline & Dt & - & - \\
\hline \multirow[t]{2}{*}{ ACT1 } & At & - & - \\
\hline & Dt & D11 & $F E^{k} ; F S^{k} ; F U^{k}$ \\
\hline
\end{tabular}

${ }^{a}$ FE Elongation; FF fineness; FL length; FS strength; FU uniformity.

${ }^{\text {b }}$ Frelichowski et al. (2006), ${ }^{c}$ He et al. (2007), d'Lacape et al. (2005), e Lin et al. (2005), ${ }^{\text {f }}$ Luan et al. (2009), ${ }^{g}$ Qin et al. (2008), ${ }^{\text {h }}$ Shen et al. (2005), ${ }^{\text {i }}$ Shen et al. (2006), ${ }^{j}$ Shen et al. (2007), ${ }^{k}$ Wang et al. (2006), ' Zhang et al. (2009) [24-34]. 
Table 4 Synonymous and nonsynonymous substitution rates in various comparisons among different cotton species

\begin{tabular}{|c|c|c|c|c|c|c|c|}
\hline \multirow[t]{2}{*}{ Gene } & \multicolumn{7}{|l|}{$\mathrm{Ka} / \mathrm{Ks} / \mathrm{Ka} \mathrm{Ks}$ ratio } \\
\hline & $A_{1}$ VS $D_{5}$ & $A_{1}$ VS Ath & $\mathrm{D}_{5}$ VS Dth & $A_{1}$ VS Atb & $\mathrm{D}_{5}$ VS Dtb & Ath VS Dth & Atb VS Dtb \\
\hline$B G$ & $\begin{array}{l}0.0081 / 0.0360 / \\
0.2243\end{array}$ & $\begin{array}{l}9.75 E-05 / 0.0098 / \\
0.001\end{array}$ & $\begin{array}{l}0.0025 / 0.0362 / \\
0.0694\end{array}$ & $\begin{array}{l}1.24 \mathrm{E}-05 / 0.0124 / \\
0.001\end{array}$ & $\begin{array}{l}0.0029 / 0.0135 / \\
0.2127\end{array}$ & $\begin{array}{l}0.0048 / 0.0282 / \\
0.1694\end{array}$ & $\begin{array}{l}0.0076 / 0.0403 / \\
0.1875\end{array}$ \\
\hline Pel & $\begin{array}{l}0.0021 / 0.0910 / \\
0.0228\end{array}$ & $\begin{array}{l}0.0024 / 0.0204 / \\
0.1198\end{array}$ & $\begin{array}{l}0.0021 / 0.0041 / \\
0.5064\end{array}$ & $\begin{array}{l}0.0012 / 0.0111 / \\
0.1106\end{array}$ & $\begin{array}{l}0.0021 / 0.0041 / \\
0.5064\end{array}$ & $\begin{array}{l}0.0022 / 0.0542 / \\
0.0398\end{array}$ & $\begin{array}{l}0.0032 / 0.0912 / \\
0.0348\end{array}$ \\
\hline ManA2 & $\begin{array}{l}0.0061 / 0.0218 / \\
0.2798\end{array}$ & $\begin{array}{l}0.0041 / 0.0137 / \\
0.2960\end{array}$ & $\begin{array}{l}0.0031 / 0.0085 / \\
0.3613\end{array}$ & $\begin{array}{l}0.0040 / 0.0164 / \\
0.2419\end{array}$ & $\begin{array}{l}0.0034 / 0.0076 / \\
0.4475\end{array}$ & $\begin{array}{l}0.0049 / 0.0177 / \\
0.2769\end{array}$ & $\begin{array}{l}0.0077 / 0.0183 / \\
0.4179\end{array}$ \\
\hline POD2 & $\begin{array}{l}0.0119 / 0.0218 / \\
0.5457\end{array}$ & $\begin{array}{l}0.0075 / 0.0069 / \\
1.0812\end{array}$ & $\begin{array}{l}0.0113 / 0.0164 / \\
0.6852\end{array}$ & $\begin{array}{l}0.0086 / 0.0195 / \\
0.4392\end{array}$ & $\begin{array}{l}0.0131 / 0.0192 / \\
0.6829\end{array}$ & $\begin{array}{l}0.0158 / 0.0313 / \\
0.5065\end{array}$ & $\begin{array}{l}0.0131 / 0.0349 / \\
0.3753\end{array}$ \\
\hline CIPK1 & $\begin{array}{l}0.0076 / 0.0308 / \\
0.2460\end{array}$ & $\begin{array}{l}0.0026 / 0.0130 / \\
0.2040\end{array}$ & $\begin{array}{l}0.0032 / 0.0134 / \\
0.2348\end{array}$ & $\begin{array}{l}0.0035 / 0.0083 / \\
0.4179\end{array}$ & $\begin{array}{l}0.0030 / 0.0117 / \\
0.2563\end{array}$ & $\begin{array}{l}0.0077 / 0.0344 / \\
0.2240\end{array}$ & $\begin{array}{l}0.0074 / 0.0247 / \\
0.3009\end{array}$ \\
\hline RacA & $\begin{array}{l}0.0117 / 0.0417 / \\
0.2811\end{array}$ & $\begin{array}{l}0.0020 / 0.0061 / \\
0.3270\end{array}$ & $\begin{array}{l}0.0093 / 0.0052 / \\
1.7812\end{array}$ & NA/NA/NA ${ }^{a}$ & $0.0067 / 0.0001 / 50$ & $\begin{array}{l}0.0143 / 0.0402 / \\
0.3554\end{array}$ & $\begin{array}{l}0.0096 / 0.0391 / \\
0.2467\end{array}$ \\
\hline $\operatorname{RacB}$ & $\begin{array}{l}1.49 \mathrm{E}-05 / 0.0149 / \\
0.001\end{array}$ & NA/NA/NA ${ }^{a}$ & NA/NA/NA ${ }^{a}$ & NA/NA/NA ${ }^{a}$ & $\mathrm{NA} / \mathrm{NA} / \mathrm{NA}^{\mathrm{a}}$ & $\begin{array}{l}1.49 \mathrm{E}-05 / 0.0149 / \\
0.001\end{array}$ & $\begin{array}{l}1.49 E-05 / 0.0149 / \\
0.001\end{array}$ \\
\hline EXP & $\begin{array}{l}0.0018 / 0.0372 / \\
0.0482\end{array}$ & $\begin{array}{l}0.0017 / 0.0335 / \\
0.0496\end{array}$ & $\begin{array}{l}0.0034 / 0.0259 / \\
0.1305\end{array}$ & NA/NA/NA ${ }^{a}$ & $\begin{array}{l}0.0034 / 0.0259 / \\
0.1305\end{array}$ & $\begin{array}{l}0.0033 / 0.0064 / \\
0.5184\end{array}$ & $\begin{array}{l}0.0016 / 0.0408 / \\
0.0394\end{array}$ \\
\hline Exp1 & $\begin{array}{l}0.0156 / 0.0562 / \\
0.2784\end{array}$ & $\begin{array}{l}0.0038 / 0.0166 / \\
0.2269\end{array}$ & $\begin{array}{l}0.0032 / 0.0221 / \\
0.1457\end{array}$ & $\begin{array}{l}0.0101 / 0.0650 / \\
0.1548\end{array}$ & $\begin{array}{l}0.0085 / 0.0174 / \\
0.4899\end{array}$ & $\begin{array}{l}0.0120 / 0.0607 / \\
0.1977\end{array}$ & NA/NA/NA ${ }^{a}$ \\
\hline $\begin{array}{l}14-3- \\
3 L\end{array}$ & $\begin{array}{l}0.0025 / 0.0299 / \\
0.0820\end{array}$ & $\begin{array}{l}5.08 \mathrm{E}-06 / 0.0051 / \\
0.001\end{array}$ & $\begin{array}{l}0.0039 / 0.0109 / \\
0.3589\end{array}$ & $\begin{array}{l}0.0019 / 3.74 \mathrm{E}-05 / \\
50\end{array}$ & $\begin{array}{l}0.0047 / 0.0233 / \\
0.2012\end{array}$ & $\begin{array}{l}0.0024 / 0.0407 / \\
0.0590\end{array}$ & $\begin{array}{l}0.0046 / 0.0036 / \\
1.2832\end{array}$ \\
\hline$C A P$ & $\begin{array}{l}0.0144 / 0.0477 / \\
0.3016\end{array}$ & $\begin{array}{l}0.0029 / 5.93 \mathrm{E}-05 / \\
48.97\end{array}$ & $\begin{array}{l}0.0036 / 0.0063 / \\
0.5721\end{array}$ & $\begin{array}{l}0.0019 / 3.84 \mathrm{E}-05 / \\
50\end{array}$ & $\begin{array}{l}0.0059 / 0.0065 / \\
0.9093\end{array}$ & $\begin{array}{l}0.0129 / 0.0437 / \\
0.2961\end{array}$ & $\begin{array}{l}0.0143 / 0.0423 / \\
0.3369\end{array}$ \\
\hline CEL & $\begin{array}{l}0.0032 / 0.0270 / \\
0.1171\end{array}$ & $\begin{array}{l}0.0014 / 0.0058 / \\
0.2392\end{array}$ & $\begin{array}{l}7.80 \mathrm{E}-06 / 0.0078 / \\
0.001\end{array}$ & $\begin{array}{l}0.0009 / 0.0038 / \\
0.2293\end{array}$ & $\begin{array}{l}0.0007 / 0.0051 / \\
0.1342\end{array}$ & $\begin{array}{l}0.0029 / 0.0400 / \\
0.0724\end{array}$ & $\begin{array}{l}0.0028 / 0.0275 / \\
0.1030\end{array}$ \\
\hline Sus 1 & $\begin{array}{l}0.0045 / 0.0318 / \\
0.1420\end{array}$ & $\begin{array}{l}0.0013 / 0.0054 / \\
0.2425\end{array}$ & $\begin{array}{l}0.0015 / 0.0070 / \\
0.2072\end{array}$ & $\begin{array}{l}0.0020 / 0.0039 / \\
0.5236\end{array}$ & $\begin{array}{l}6.31 \mathrm{E}-06 / 0.0063 / \\
0.001\end{array}$ & $\begin{array}{l}0.0053 / 0.0253 / \\
0.2079\end{array}$ & $\begin{array}{l}0.0013 / 0.0054 / \\
0.2425\end{array}$ \\
\hline CelA1 & $\begin{array}{l}0.0028 / 0.0406 / \\
0.0689\end{array}$ & $\begin{array}{l}0.0005 / 0.0097 / \\
0.0479\end{array}$ & $\begin{array}{l}0.0005 / 0.0027 / \\
0.1965\end{array}$ & $\begin{array}{l}1.06 \mathrm{E}-05 / 0.0106 / \\
0.001\end{array}$ & $\begin{array}{l}4.40 E-06 / 0.0044 / \\
0.001\end{array}$ & $\begin{array}{l}0.0038 / 0.0403 / \\
0.0939\end{array}$ & $\begin{array}{l}0.0027 / 0.0443 / \\
0.0612\end{array}$ \\
\hline CelA3 & $\begin{array}{l}0.0066 / 0.0406 / \\
0.1615\end{array}$ & $\begin{array}{l}0.0035 / 0.0074 / \\
0.4772\end{array}$ & $\begin{array}{l}0.0027 / 0.0284 / \\
0.0967\end{array}$ & $\begin{array}{l}0.0043 / 0.0069 / \\
0.6208\end{array}$ & $\begin{array}{l}0.0037 / 0.0219 / \\
0.1683\end{array}$ & $\begin{array}{l}0.0025 / 0.0230 / \\
0.1067\end{array}$ & $\begin{array}{l}0.0050 / 0.0264 / \\
0.1904\end{array}$ \\
\hline LTP3 & $\begin{array}{l}0.0631 / 0.0752 / \\
0.8401\end{array}$ & $\begin{array}{l}\text { 2.37E-05/0.0237/ } \\
0.001\end{array}$ & NA/NA/NA ${ }^{a}$ & $\begin{array}{l}1.00 E-05 / 0.0100 / \\
0.001\end{array}$ & NA/NA/NA ${ }^{a}$ & $\begin{array}{l}0.0610 / 0.0858 / \\
0.7111\end{array}$ & $\begin{array}{l}0.0620 / 0.0667 / \\
0.9289\end{array}$ \\
\hline ACT1 & $\begin{array}{l}0.0013 / 0.0445 / \\
0.0284\end{array}$ & $\begin{array}{l}0.0012 / 0.0088 / \\
0.1381\end{array}$ & $\begin{array}{l}4.43 E-05 / 0.0443 / \\
0.001\end{array}$ & $\begin{array}{l}0.0012 / 0.0088 / \\
0.1381\end{array}$ & $\begin{array}{l}4.08 E-05 / 0.0408 / \\
0.001\end{array}$ & $\begin{array}{l}6.53 \mathrm{E}-05 / 0.0653 / \\
0.001\end{array}$ & $\begin{array}{l}5.37 E-05 / 0.0537 / \\
0.001\end{array}$ \\
\hline
\end{tabular}

Letter designations are the same as in Table 2.

${ }^{a}$ no synonymous and nonsynonymous site.

excluded from our analysis, the "NAs" were considered zero when they were compared with others whose Ks were not NA. In all pairwise comparisons of nucleotide diversity for each gene between subgenomes within a species [32 pairs, 16 in TM-1 and 16 in Hai7124 ( $R a c B$ was excluded)], $62.5 \%$ (10 in TM-1 and 10 in Hai7124) had a higher evolutionary rate in the D-subgenome than in the A-subgenome. Furthermore, in the 16 gene pairs (excluding $R a c B$ ) from the A-subgenomes of TM-1 and Hai7124, $62.5 \%$ (10 out of 16) had a higher evolutionary rate in TM-1 than in Hai7124, 31.25\% (5 of 15) and were reversed and $6.25 \%$ ( 1 of $16, A C T 1$ ) showed an equivalent evolutionary rate between TM-1 and Hai7124. Similarly, in the 15 gene pairs ( $R a c B$ and LTP3 were excluded) from the D-subgenomes of TM-1 and Hai7124, 60\% (9 of 15) had a higher evolutionary rate in TM-1 than in Hai7124, 26.67\% (4 of 15) and were reversed and $13.33 \%$
(2 of 15, Pel and Exp) showed an equivalent evolutionary rate between TM-1 and Hai7124.

Phylogenetic relationships are reflected in the nucleotide substitution results (Additional file 3: Supplemental Figure S2). Based on branch length, all of homeologs from the two tetraploid species had unequal rates of sequence evolution following allopolyploid formation. The rates at which the deviations occurred in allopolyploids are sufficient to generate branch length inequality between the A- and D-subgenomes [35].

$\mathrm{Ka} / \mathrm{Ks}$ ratio comparisons showed that selection had altered the molecular evolutionary rate of some genes due to allopolyploid formation. Four genes, Pel, RacA, Exp and Sus1, in TM-1, and five genes, Pel, CIPK1, 143-3L, CAP and CelA3, in Hai7124, yielded higher $\mathrm{Ka} / \mathrm{Ks}$ ratios in A-At, D-Dt and At-Dt comparisons than in the A-D comparison, indicating that selection for some 
genes related with fiber development had acted at the tetraploid level.

\section{Differential expression fiber development genes}

After the specificity of homeolog-specific primer pairs were confirmed by PCR amplification of genomic DNA from G. herbaceum (A-genome), G. raimondii (D-genome), TM-1 and Hai7124 (Figure 1), their homeolog transcripts in young tetraploid cotton fiber were further detected by qPCR analysis. The relative expression values at 10 different fiber development stages were obtained by combining the homeolog transcripts of each gene at the same stage. Expression for the 17 genes could be broken down into five categories (Additional file 6: Supplemental Figure S3): 1) fiber initiation and early elongation (0-8 DPA), such as Exp, POD2 and ManA2 (Additional file 6: Supplemental Figure S3A); 2) fiber elongation (3-17 DPA), such as Exp1, Pel, and LTP3 (Additional file 6: Supplemental Figure S3B); 3) primary-secondary transition period (17-23 DPA), such as BG, CEL and CelA1 (Additional file 6: Supplemental Figure $\mathrm{S} 3 \mathrm{C}$ ); 4) both at fiber initiation and early elongation period (0-8DPA) and secondary cell wall thickening period (20-23DPA), such as Sus1, 14-3-3L and RacB (Additional file 6: Supplemental Figure S3D); 5) the whole fiber developmental period, such as CelA3, CAP, ACT1, RacA and CIPK1 (Additional file 6: Supplemental Figure S3E). In the last category, however, transcript preference was shown at some stages. For example, CelA3 and CAP were expressed preferentially at the fiber elongation and secondary cell wall thickening stages (8-23 DPA), but had moderate expression at 0-5 DPA.

Gene expression differences in TM-1 and Hai7124 were further clarified by statistical analysis of least signification difference (LSD). Greater expression in Hai7124 than in TM-1 was observed for 14-3-3L except at 20 DPA, and for CelA3 except at 5, 17 and 23 DPA. Other gene transcripts showed different expression advantages in the two cotton species at various fiber developmental stages.

At fiber initiation and early elongation (0-8 DPA), most genes, including Exp, ManA2, Sus1, RacB, CelA3, $C A P$ and $\operatorname{Rac} A$, had significantly higher expression levels

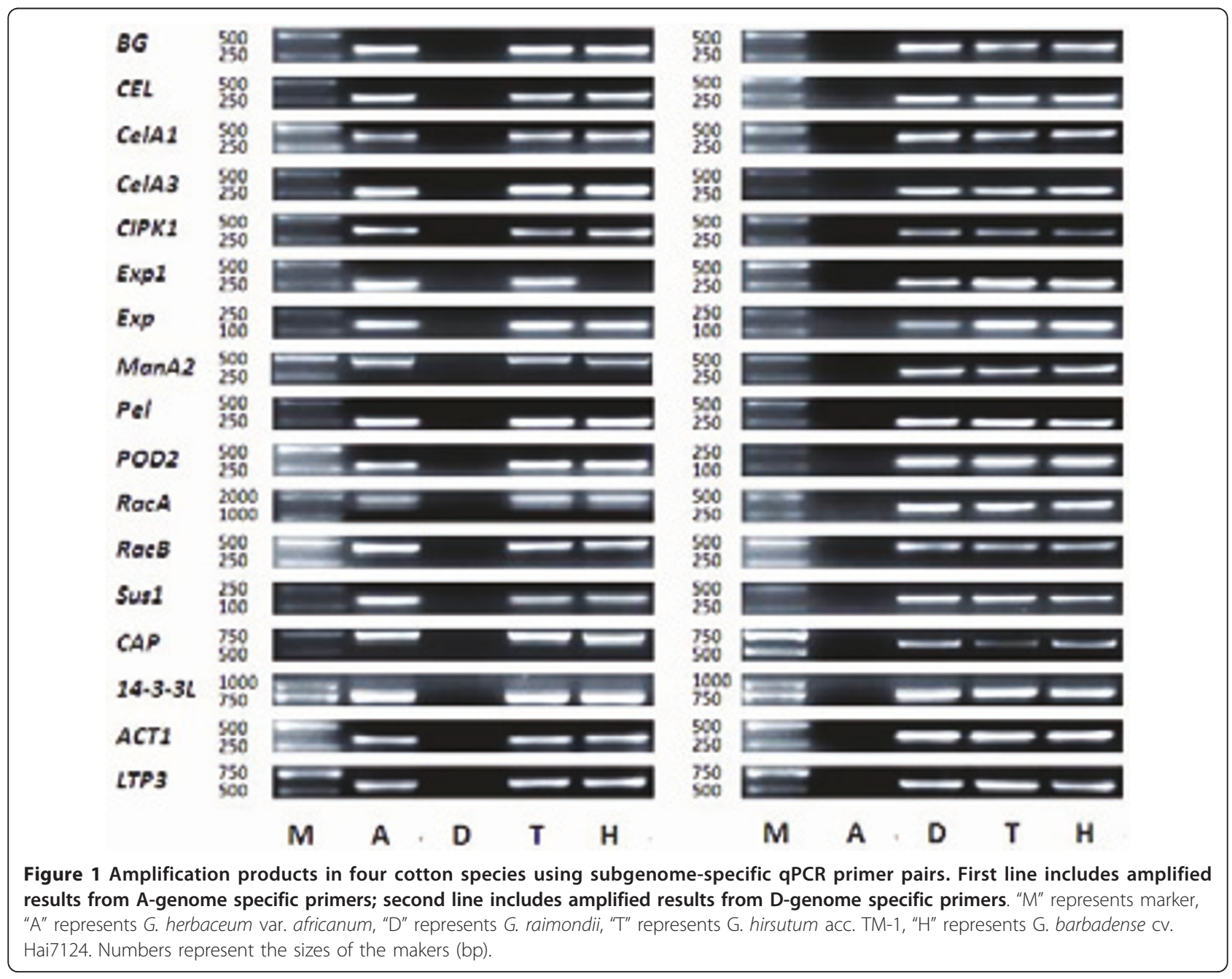


in Hai7124 than in TM-1. During fiber elongation (5-14 DPA), the expression profiles of genes preferentially expressed during that period were either biased to TM1 or Hai7124 or were equally expressed between the two. Five genes, Exp1, Pel, CAP, CIPK1 and RacA, were expressed preferentially in TM-1 or equally between TM-1 and Hai7124, except at 8 DPA, that these same genes showed significantly greater expression levels in Hai7124; LTP3 and ACT1 showed significantly higher expression levels in TM-1 than in Hai7124; expression of CelA3 was higher in Hai7124.

During primary-secondary cell wall transition (17-23 DPA), peak expression occurred earlier in TM-1 than in Hai7124 for most genes (CAP, CelA3, CIPK1, CEL, BG, RacB, Sus1 and 14-3-3L). ACT1 and RacA expressed equally in TM-1 and Hai7124 at 17 and 20 DPA, but significantly greater in Hai7124 at 23 DPA. The extended fiber development period, as indicated by higher expression at a later DPA, may help explain why G. barbadense has an extra long staple cotton. One gene, CelA1, showed no significant expression difference between TM-1 and Hai7124.

\section{Genome-specific expression of the homeologs}

Based on the homeolog expression profile, 17 diagnostic genes in TM-1 and 17 in Hai7124 were further evaluated. Of the 34 genes, $32.35 \%$ (11) were equally expressed between the A- and D-subgenomes, $41.18 \%$ (14) were A-subgenome biased, 20.59\% (7) were D-subgenome biased and $5.88 \%$ (2) were A- or D-biased at different stages.
The 17 fiber development genes were clustered into three comparison patterns between TM-1 and Hai7124. First, homeologs for CelA3, Exp, Exp1 and CIPK1 in both TM-1 and Hai7124 were equally expressed between the A- and D-subgenomes in the preferentially-expressed stages (Figure 2). Of these, Exp1 had equal transcript levels from the two homeologs in TM-1 and Hai7124, with two distinguishable copies in TM-1 and two undistinguishable copies in Hai7124. These data were consistent with the fact that the duplicated loci for Exp1 in Hai7124 had the same sequence as the D-subgenome (Figure 2).

Second, the transcripts of 11 genes, CEL, Pel, Sus1, 14-33L, RacA, CelA1, ManA2, RacB, CAP, LTP3 and POD2, were A- or D-subgenome biased (Figure 3). Among these, CEL, Pel, Sus1, 14-3-3L and RacA were A-subgenome biased and CelA1, ManA2 and RacB were D-subgenome biased in both TM-1 and Hai7124 at all stages. The transcripts of the homeologs of CAP, LTP3 and POD2 were significantly altered in the preferentially expressed stages in TM-1 and Hai7124. In TM-1, the transcripts of CAP and LTP3 were significantly A-subgenome biased. However, the transcripts of the two genes in Hai7124 were equivalently expressed at most stages, only D-subgenome bias in LTP3 in the primary-secondary cell wall transition period detected. Expression of $P O D 2$ was A-subgenome biased at 0, 3 and 10 DPA and D-subgenome biased at 1 DPA in TM-1. In Hai7124, POD2 expression was A-subgenome biased at 0,3 and 10 DPA and D-subgenome biased at 1, 5 and 8 DPA.

Third, $B G$ was significantly $(\mathrm{P}<0.001)$ affected only from the A-subgenome, and $A C T 1$ was significantly $(\mathrm{P}<$

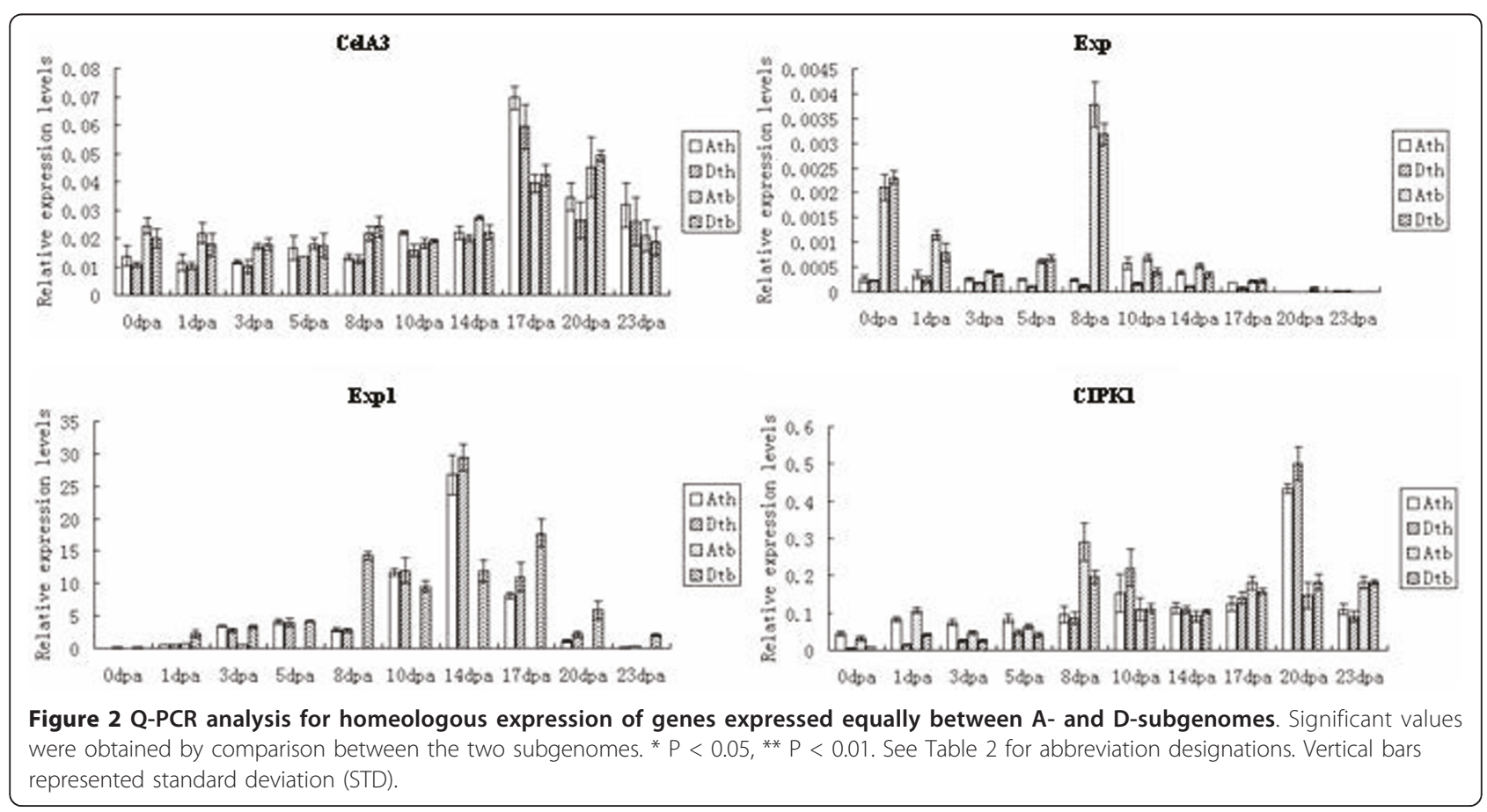


CEL
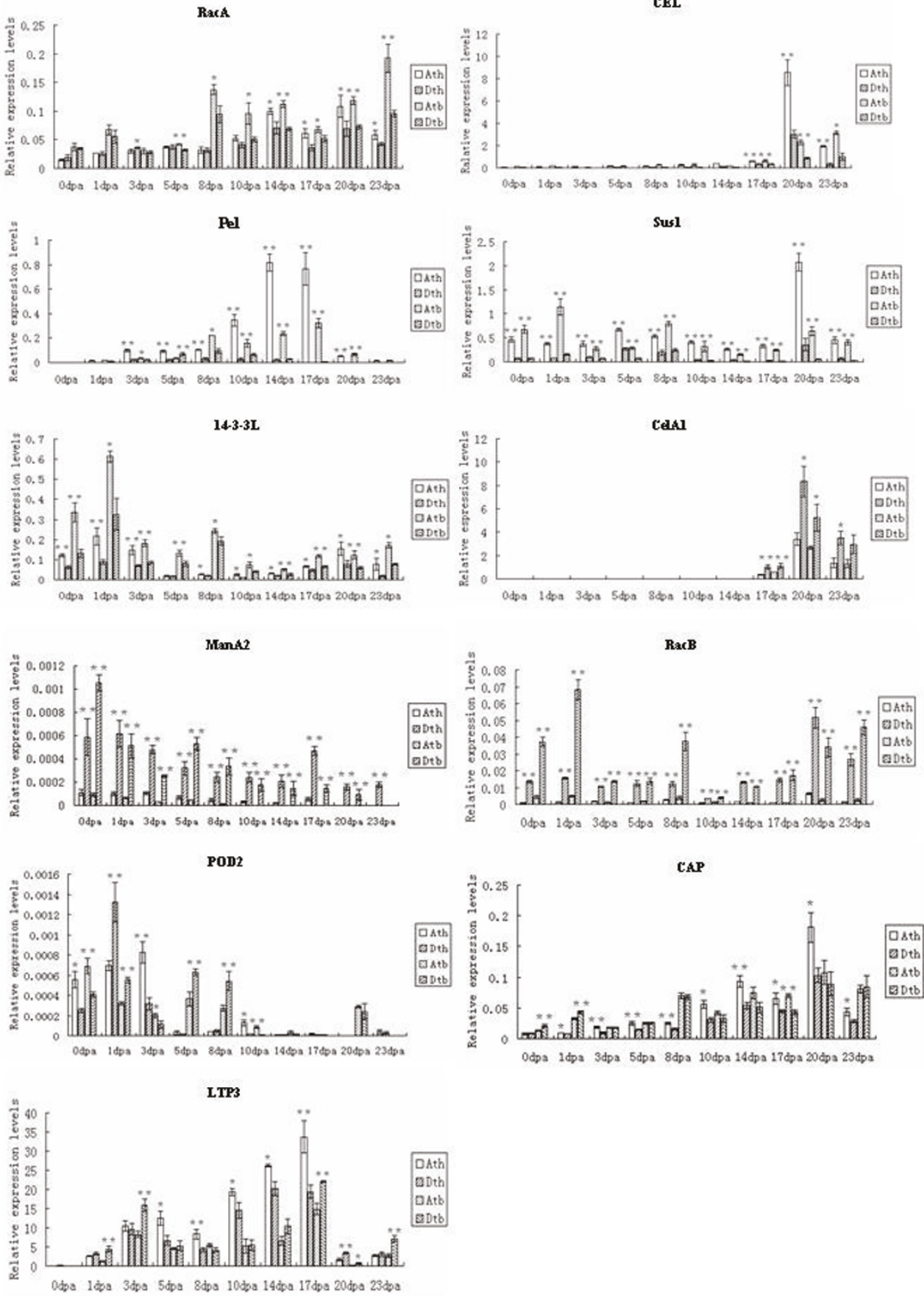

Figure 3 Q-PCR analysis for homeologous expression of genes with A or D-subgenome biased expression. Significant values and vertical bars were same with Figure 2 .

0.001) affected from the D-subgenome at all stages in both TM-1 and Hai7124 (Figure 4). Based on the comparison patterns and the structural analysis of the two genes, we proposed that the homeolog of $B G$ from the D-subgenome might be silenced and that of $A C T 1$ from the A-subgenome may have novel roles in other species (neofunctionalization).
Differences between TM-1 and Hai7124 in transcriptome contributions of the subgenome at key fiber developmental stages were detected. During initiation and early elongation of the fiber, 10 gene transcriptions showed greater expression levels in Hai7124 than in TM-1. Of those, the D-subgenome contributed higher amounts of $A C T 1, \operatorname{RacB}$ and Man2, while the A- 

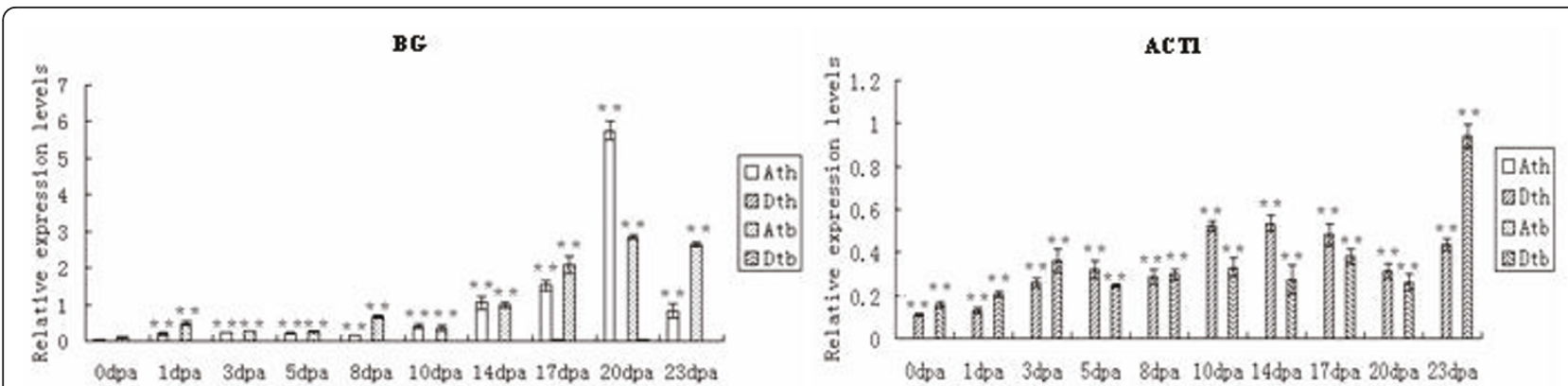

Figure 4 Q-PCR analysis for homeologous expression of genes with subgenome-specific expression. Significant values and vertical bars were same with Figure 2

subgenome contributed higher amounts of Sus1, CIPK1 and 14-3-3L. CelA3, Exp, CAP and RacA were equally supplied by both subgenomes.

At $8 \mathrm{DPA}$, corresponding to the close of fiber plasmodesmate [36], the transcriptions of 12 genes (Exp1, Pel, POD2, CelA3, BG, Sus1, CAP, Exp, RacA, RacB, 14-3-3L and CIPK1) were sharply accumulated in Hai7124. Of those, the transcripts of $R a c B$ and $P O D 2$ were contributed mainly from D-subgenome, that of BG, Pel, Sus1 and RacA from A-subgenome and others by both A- and D-subgenomes.

At the primary-secondary transition period, the expression of 10 genes, CelA3, CAP, ACT1, RacA, CIPK1, 14-3-3L, Sus1, RacB, CEL and BG, occurred earlier in TM-1 than in Hai7124. The transcripts of $A C T 1$ and $\operatorname{RacB}$ were mainly from $\mathrm{D}$-subgenomes; those of $B G, C E L$ and Sus1 were mainly from A-subgenomes, and other genes were from both A- and D-subgenomes. Based on these data we inferred that the expression accumulation of the A-subgenome, or the combination of A- and D-subgenomes, played critical roles in fiber quality divergence of G. hirsutum and G. barbadense. However, the expression of D-subgenome alone also played an important role.

\section{Discussion}

\section{Evolutionary fate of duplicated genes}

For each gene that was studied, allopolyploid species should have two homelogs, representing descendants from the A-genome and D-genome donors at the time of polyploidy formation. Cronn et al. [35] indicated that most duplicated genes in allopolyploid cotton evolved independently of each other. Our phylogenetic analyses support this hypothesis, and the independent evolution of several genes was distinctively evident in their structure, in our study. For example, CAPs and RacBs had the same structure between each diploid and its counterpart in allopolyploid cotton (A- and At-subgenome, $\mathrm{D}$ - and Dt-subgenome), but the different structures were apparent in the A-D comparison (Additional file 2: Supplemental Figure S1B). Though expression of ManA2 from the At-subgenome of Hai7124 ceased rather early in the growth process, the structure difference between the A-, At-subgenomes and D-, Dt-subgenomes was also distinct. The fact that the structure of the At- and Dt-subgenomes mirrored their putative ancestral diploid species suggested the difference may have occurred before allopolyploid formation and evolved independently in allopolyploid cotton. CelA3s from At-subgenome of TM-1 and Hai7124 displayed the same mutation, which altered their coding regions, indicating not only independent evolution, but also parallel evolution between TM-1 and Hai7124. This change, however, was not detected in their putative ancestral diploid species, suggesting accelerated evolution of CelA3 in the At-subgenome after allopolyploid formation. Though most genes independently evolved in allopolyploid cotton, there were some exceptions. For example, Exp1 from At-subgenome were colonized in Hai7124 by Dt-subgenomes.

Relative to expression, duplicate genes can follow one of three evolutionary paths. First, one copy may evolve into a nonfunctional pseudogene [37-41]. Second, the multiple copies can contribute to an increase in the gene expression level $[42,43]$ or both copies can suffer mutations but the combined action of both gene copies is necessary to maintain original function and expression levels (subfunctionalization) $[40,44,45]$. Third, one copy may gain a novel beneficial function (neofunctionalization) that is selectively maintained within the genome [40,46-48]. We measured homeolog-specific contributions to the transcriptome in allopolyploid cotton fiber by Q-PCR analysis. Because the majority $(64.70 \%)$ of diagnostic genes exhibited subgenome-specific bias to the A or D-subgenome, subgenomebiased expression in cotton fiber developmental stages was considered commonplace. This result was consistent with previous studies [49-55]. Most of genes in our study exhibited the same expression bias in the two cultivated cotton species, TM-1 and Hai7124. However, some inconsistencies were detected in three genes (CAP, LTP3 and POD2), suggesting that these genes may have had different roles in the interspecific divergence between G. hirsutum and G. 
barbadense. Artificial selection by humans of certain desirable fiber traits may have also influenced G. hirsutum and G. barbadense genetic structure [55].

Synthesizing structures and expression profiles of the duplicates, their possible fates are inferred. $B G$ accumulated solely in A-subgenome transcripts ( $\mathrm{D}$-subgenome silenced), in both TM-1 and Hai7124 (Figure 4). BGs obtained from the D-subgenomes of TM-1 and Hai7124 had a nucleotide deletion and a nonsense mutation, respectively, which altered the ORFs (Table 2). The structure difference suggests that $B G$ in the D-subgenomes of TM-1 and Hai7124 may be pseudogenes. On the other hand, while CAP and CelA3 had different A- and D-subgenome structures in both TM-1 and Hai7124 (Additional file 2: Supplemental Figure S1B), their A- and D-subgenome expression profiles were active (Figure 2, 3). Therefore, the duplicated genes of CAP and CelA3 may be subfunctionalized. Similarly, the functions of duplicated genes from CEL, Sus1, 14-3-3L, RacA, RacB, Exp, Exp1, CIPK1, CelA1, Pel, ManA2, LTP3 and POD2 were also subfunctionalized (Figure 3). Because ACT1 transcripts of A subgenomes could not be detected at all stages of fiber development (Figure 4), they may have evolved new functions.

\section{Domestication of allopolyploid cotton}

Numerous plant species have been selectively bred over the course of human social evolution [56]. Allopolyploid cotton species are believed to have formed about 1-2 million years ago, by hybridization between a maternal Old World diploid A-genome G. herbaceum [57] and paternal New World diploid D-genome G. raimondii [57-59]. The allotetraploid lineage gave rise to five extant tetraploid species, including G. barbadense and G. hirsutum, known for their superior fiber quality and high yield, respectively. In the present study, the $\mathrm{Ka} / \mathrm{Ks}$ ratios among four cotton species indicated that selection of fiber development genes occurred at the tetraploid level. By comparing the nucleotide diversity between TM-1 and Hai7124 within the same subgenome, most genes $(62.5 \%$ in $\mathrm{A}$-subgenome and $60 \%$ in $\mathrm{D}$-subgenome) had a higher evolutionary rate in TM-1 than in Hai7124, which may be associated with longer and more frequent cultivation of TM-1. Given these data, we propose that diversity evolution between A- and D-subgenomes within a species or between TM-1 and Hai7124 within the same subgenome was due to both natural and artificial selection pressure [55].

\section{Gene expression differences between TM-1 and Hai7124}

G. hirsutum and G. barbadense are two domesticated cotton species possessing very different agronomic and fiber quality characteristics with G. barbadense having superior fiber quality. Rapp et al. (2010) studied the transcriptomes of cotton fibers from wild and domesticated accessions (G. hirsutum) and found that human selection during the initial domestication and subsequent crop improvement had resulted in a biased upregulation of components of the transcriptional network during fiber development [60]. In this study, of the 17 fiber development-related genes, 14 had the similar expression pattern and three that did not, in TM-1 and Hai7124 (Figure 2, $3,4)$. Of three genes, the transcripts of homeologs were significantly A- or D-subgenome biased in TM-1. However, in Hai7124, homeolog transcripts were equally expressed between the two subgenomes or D-subgenome biased. Though 14 genes had the same expression patterns between TM-1 and Hai7124, the relative expression levels were different at most stages. While the same Aor D-biased or equal expression profile in the two cultivated cotton species might be related to functional partitioning of genomic contributions during cellular development after allopolyploid formation, significant alternation of homoelog A/D ratio and expression difference at the same fiber developmental time points between G. hirsutum and G. barbadense indicated that domestication for different fiber qualities may play an important role in fiber quality divergence of G. hirsutum and G. barbadense.

In previous study, fiber growth curves have shown longer fiber elongation phases in domesticated G. hirsutum than that in wild G. hirsutum, and further comparative gene expression profiling of isolated cotton fibers over a developmental time course of fiber differentiation indicated that domesticated TM-1 displayed a much higher level of transcriptional variation between the sampled time points than the wild accession did [60]. In the study, the expression peak of transcripts in most genes was earlier in TM-1 than in Hai7124, especially at the primary-secondary transition period, which indicated that most genes related to fiber development expressed longer and more intensely in Hai7124. Resulting differences in mRNA levels may lead to changes in enzyme activity, further contributing to phenotypic differences between the two cotton species. Several genes that are differentially expressed in TM-1 and Hai7124 should be further mined.

The 14-3-3 protein is an important regulatory protein. Shi et al. [6] proposed that the Gh14-3-3L transcripts are highly accumulated during early cotton fiber development, suggesting that Gh14-3-3L may be involved in regulating fiber elongation. Our data showed that, although $14-3-3 L$ is expressed preferentially in the early development stages of cotton fibers in both TM-1 and Hai7124, the relative expression values were significantly different. The expression of 14-3-3L was significantly higher in most stages in Hai7124 (Additional file 6: Supplemental Figure S3E), than in TM-1. Furthermore in the primary-secondary transition period of fiber development, a secondary expression peak of $14-3-3 L$ was 
also detected, indicating 14-3-3L may also be involved in thickening of the secondary cell wall, a function that has been reported in other species [61]. At 23 DPA, the expression of 14-3-3L decreased in TM-1, but was still increasing in Hai7124, suggesting a longer transcriptional period.

CelA1 was solely expressed during secondary wall cellulose synthesis, with no significant expression difference between TM-1 and Hai7124 (Additional file 6: Supplemental Figure S3C). The importance of CelA genes in secondary wall cellulose synthesis in developing cotton fibers has been reported by other researchers [16]. Expression of CelA3 at 17 DPA was significantly higher in TM-1 than in Hai7124. However, strength dropped much faster in TM-1 (e.g., at 20 DPA, Additional file 6: Supplemental Figure S3E) than in Hai7124 after that, which more stable expression was detected over a longer period of time in Hai7124.

Rac genes (coding for GTP-binding Rac proteins) are involved in various physiological processes, including cell polar growth [62-65], synthesis of the secondary wall [66-68], resistance response $[69,70]$ and signal transduction [71-73]. In the present study, RacAs were predominantly expressed at the fiber elongation and secondary wall synthesis stages (Additional file 6: Supplemental Figure S3E), indicating that the role of RacA may be similar to that of Rac13, which is involved in the signal transduction pathway for cytoskeleton organization [66]. Similarly, $\operatorname{RacB}$ was predominantly expressed at the secondary wall synthesis stage in TM-1, and preferentially expressed at the initiation of fiber development and secondary wall synthesis in Hai7124 (Additional file 6: Supplemental Figure S3D), suggesting multiple roles for $R a c B$. Because $R a c A$ and $R a c B$ expressions were consistently higher at most stages in Hai7124 relative to $\mathrm{TM}-1$, the two genes may be contributing to fiber quality diversity.

Sucrose synthase (Sus) affects initiation and elongation of the single-celled fibers, and also has a major role in cell wall cellulose synthesis [9,74-77]. Cotton fiber cell initiation and elongation are very sensitive to changes in Sus activity [9]. The expression peak of cotton sucrose synthase genes transcripts was earlier in wild cotton than in TM-1[60]. Our study showed that greater Sus1 expression in Hai7124 than in TM-1 at initiation (0 and 1 DPA) and 8 DPA and at 3 and 5 DPA was reversed. At 20 DPA, Sus1 expression was significantly higher in TM-1, possibly as a result of earlier termination of fiber elongation and earlier initiation of cell wall synthesis in TM-1.

Recent studies of comparative gene expression profiling of isolated cotton fibers $[60,78]$ have identified genes controlling differences in fiber growth between wild and domesticated cotton [e.g., genes encoding tubulin isoforms, endotransglycosylase/hydrolases, cytochrome
$\mathrm{P}(450)$ monooxygenase, and antioxidant enzymes]. These studies will provide new clues in the future studies to better understand the interspecific divergence of fiber development in the two cultivated tetraploid cotton species, G. barbadense and G. hirsutum.

\section{Putative role of D-subgenome in interspecific divergence} Most genes (62.5\% in TM-1 and 62.5\% in Hai7124) exhibited a higher evolutionary rate in the D-subgenome than in the A-subgenome, indicating that the D-subgenome of the allotetraploid evolved faster than the A-subgenome [59,79-82]. Considering the weight of evidence provided by genome-specific expression of homeologs, chromosome location of genes and QTL distribution for fiber qualities (Table 3), we also determined the subgenome transcriptome contribution in interspecific divergence between TM-1 and Hai7124. In the integration interval of genes and QTLs, the gene transcripts were significantly A-subgenome biased, and the QTLs associated with fiber qualities were detected in corresponding A-subgenome chromosome bins. Similarly, the gene transcripts were significantly D-subgenome biased and relative fiber QTLs were detected in corresponding D-subgenome chromosome bins. While the transcripts of CAP was significantly A-subgenome biased in TM-1, but equally expressed in Hai7124 in the fiber developmental period, implying an important D-subgenome contribution for elite fiber quality traits in Hai7124. Integration of CAP duplicated loci with fiber length and strength QTLs in D13, indicates domestication and artificial selection of tetraploid plants for superior fiber quality resulted in more significant evolutionary dynamics in the $\mathrm{D}$-subgenome than in the A-subgenome.

\section{Conclusion}

The study provided us the systematic report on the interspecific divergence for fiber development between Gossypium barbadense and G. hirsutum by analyzing structures, molecular evolution and transcripts levels of fiber development-related genes. The results indicated that selective breeding for certain desirable fiber qualities may have played an important role in divergence of the two cultivated tetraploid cotton species.

\section{Methods}

\section{Plant materials}

Of the 17 genes selected for this study (Table 1) were described in previous reports as being expressed in developing cotton fibers; their sequence information was deposited in GenBank. The orthologous loci of each of the 17 genes were isolated from two allotetraploid cottons, G. hirsutum acc. TM-1, G. barbadense cv. Hai7124, and living models of their two ancestral genome donors, G. herbaceum var. africanum (A-genome) and G. raimondii Ulbrich (D-genome). For expression 
analysis, developing cotton ovules and attached fibers were harvested from three replicates of TM-1 and Hai7124 on $0,1,3,5,8,10,14,17,20$ and 23 days postanthesis (DPA). The mapping population was comprised of $138 \mathrm{BC}_{1}$ individuals generated from the cross [(TM$1 \times$ Hai7124) $\times$ TM-1] [19].

\section{PCR amplification, cloning and sequencing}

Based on GenBank deposited sequences, gene-specific PCR primer pairs were individually designed for PCRamplification of full-length sequences of the 17 genes. For the smaller genes, we designed one primer pair; at least two nested primer pairs were designed for the larger genes (Additional file 1: Supplemental Table S1).

Standard polymerase chain reaction (PCR) was completed using High-fidelity ExTaq DNA polymerase (TaKaRa Biotechnology (Dalian) Co., Ltd., China). The PCR products were cloned into pMD18-T Vector (TaKaRa) according to the manufacturer's instructions, and sequenced from plasmid DNA templates. In order to obtain the sequence from both the A-subgenome and D-subgenome, at least 10 clones for each gene from each of the tetraploid species, TM-1 and Hai7124, were picked randomly and sequenced. Homeologs were identified by comparison to sequences from their diploid progenitors. To avoid possible complications originating from PCR recombination in allopolyploid cotton [83], a minimum of three clones was used to determine the gene sequence in each duplicated copy. In cases where PCR recombination occurred, 10 additional clones were sequenced to verify the corresponding correct sequence [83]. When the copy number of genes was difficult to identify by sequencing, it was confirmed by southern blot analysis.

Lengths were determined using alignment analysis, which was applied to each relevant sequence of applicable gene. For genes with one primer pair, the A- and D-subgenome sequences were clustered using the Neighbor-Joining method in MEGA3.1 http://www. megasoftware.net/. For those genes having more than one primer pair, sequence segments from the same genomes and subgenomes were contiged by CAP3 software.

\section{Gene structure and phylogenetic analyses}

Six DNA sequences for each gene, including homeologs and orthologs, isolated from the four species (A-, $\mathrm{D}$-genome and the $\mathrm{A}$ and $\mathrm{D}$ subgenome from the allotetraploid), were aligned by ClustalX http://www.ebi.ac.uk/ Tools/msa/clustalw2/. Based on the sequences of genomic DNA and the cDNA, the structure of each gene was illustrated by the Gene Structure Display Server (GSDS, http://gsds.cbi.pku.edu.cn/chinese.php). Phylogenetic analyses of the orthologs for each gene were performed using the Neighbor-Joining method in MEGA3.1 http://www.megasoftware.net/.

\section{Chromosomal location}

In order to locate all 17 pairs of homeologs on our genetic map, PCR primers were designed according to the sequence size difference between the two allotetraploid cottons (Additional file 4: Supplemental Table S2). For homeologs with no size polymorphism, singlenucleotide amplified polymorphism (SNAP) primers were designed based on a SNP between the TM-1 and Hai7124 sequences at a putative locus (Additional file 5: Supplemental Table S3). SNAP is a modified allele-specific amplified method, it introduce an additional base pair change in the primer to increase the specificity of the primer [84]. All SNAP primers was designed following Drenkard et al. [84] and using SNAPER http://ausubellab.mgh.harvard.edu.

All the primer pairs exhibiting polymorphisms between TM-1 and Hai7124 were used to survey 138 individuals of the $\mathrm{BC}_{1}$ mapping population. The polymorphic loci were integrated in our backbone map [22] using Joinmap 3.0 software [85].

\section{Evolution and ratios of sequence forms}

For each gene, synonymous substitution rates (Ks), nonsynonymous substitution rates (Ka) and their ratios $(\mathrm{Ka} / \mathrm{Ks})$ in various comparisons among the four species $\left(A_{1}\right.$ VS $D_{5}, A_{1}$ VS At, $D_{5}$ VS Dt, At VS Dt) were calculated for the coding region using $\mathrm{KaKs}$ _Calculator http://sourceforge.net/projects/kakscalculator2/. Ks is the rate of evolution and the $\mathrm{Ka} / \mathrm{Ks}$ ratio indicates the selective force acting on the protein [86]. A Ka/Ks ratio of 1 represents neutral evolution, that is, the number of nonsynonymous changes at each possible nonsynonymous site is the same as the number of synonymous changes per synonymous site. $\mathrm{Ka} / \mathrm{Ks}<1$ indicates a purifying selection (selection generally eliminates deleterious mutations and maintains protein status quo); $\mathrm{Ka} / \mathrm{Ks}>1$ indicates positive selection, where selection may be modifying the protein. The higher the ratio is, the stronger the evidence that selection is occurring.

\section{Development of homeolog-specific PCR primer pairs}

Homeolog-specific primers were designed and applied based on sequence differences between duplicated loci (Additional file 7: Supplemental Table S4). Specificity of those primers was detected by PCR amplification of genomic DNA from G. herbaceum (A-genome), G. raimondii (D-genome), TM-1 and Hai7124. Primers specific for the A-genome resulted in amplifications from G. herbaceum, TM-1 and Hai7124, but not from G. raimondii, which indicated that the amplification products of TM-1 and Hai7124 were from their A-subgenomes. Conversely, the D-genome specific primers only amplified from G. raimondii and D-subgenome of the allopolyploid. 


\section{RNA isolation and Q-PCR analysis}

Total RNA was extracted from young fibers of $G$. hirsutum acc. TM-1 and G. barbadense cv. Hai7124 at 0, 1, 3, 5, 8, $10,14,17,20$ and 23 DPA using the CTAB-acid phenol extraction method [87]. RNA samples were treated with DNase I (Ambion, Austin, TX, USA) according to manufacturer's instructions to remove trace contaminants of genomic DNA. Total RNA samples $(1 \mu$ g per reaction) were reversely transcribed into cDNAs by avian myeloblastosis virus (AMV) reverse transcriptase, and the cDNAs were used as templates in Q-PCR reactions.

For each gene, the homeolog-specific primers were designed based on the SNP between A- and D-subgenome homeologs (Additional file 7: Supplemental Table S4). A cotton elongation factor (EF1a) gene was used as a standard control in the Q-PCR reactions (Additional file 7: Supplemental Table S4). The Q-PCR reaction and calculated relative value for expression level of each homeolog were determined as described by Wang et al. [8]. The information of the Q-PCR analysis based on the MIQE checklist was submitted in Additional file 8.

\section{Additional material}

Additional file 1: Table S1. Primer pairs used for amplifying the fulllength genomic sequences of each gene.

Additional file 2: Figure S1. Structure analysis of fiber developmentrelated genes in four cotton species. A: G. herbaceum L. var. africanum; D: G. raimondii Ulbr; TM-1-At: A subgenome of G. hirsutum L. acc. TM-1; TM1-Dt: D subgenome of G. hirsutum L. acc. TM-1; 7124-At: A subgenome of G. barbadense L. Cv. 7124; 7124-Dt: D subgenome of G. barbadense L. CV. 7124. A. Orthologs having the same structures among four different cotton species. B. Orthologs having different structures among four different cotton species.

Additional file 3: Figure S2. The phylogenetic trees of 17 genes in four cotton species. Bootstrap values (\%) based on 1000 replicates are indicated beside the nodes. A. Genes that evolved independently between the A- and D-subgenomes. B. Genes that evolved through different degrees of colonization between the A- and D-subgenome.

Additional file 4: Table S2. PCR primer pairs used for gene location. Additional file 5: Table S3. SNP primer pairs used for gene location. Additional file 6: Figure S3. Q-PCR analysis for total expression of genes. Significant differences between TM-1 and Hai7124 at the same stages indicated by ${ }^{*} P>0.05,{ }^{* *} P>0.01$. Vertical bars represented standard deviation (STD). A. Genes expressed preferentially at fiber initiation and early elongation (0-8 DPA). B. Genes expressed preferentially at fiber elongation (3-17 DPA). C. Genes expressed preferentially at primary-secondary transition (17-23 DPA). D. Genes expressed both at fiber initiation and early elongation period (0-8DPA) and secondary cell wall thickening period (20-23DPA). E. Genes expressed coving the whole fiber developmental period.

Additional file 7: Table S4. Subgenomic-specific PCR primer pairs used for Q-PCR analysis.

Additional file 8: The information of the Q-PCR analysis based on the MIQE checklist.

\section{Abbreviations}

SNP: Single Nucleotide Polymorphism; SNAP: Single-Nucleotide Amplified Polymorphisms; QTL: Quantitative Trait Loci.

\section{Acknowledgements}

We thank RJ Kohel at U. S. Department of Agriculture-Agricultural Research Service, Southern Plains Agricultural Research Center, ZJ Chen at Institute for Cellular and Molecular Biology and Center for Computational Biology and Bioinformatics, University of Texas, and JE Zalapa at Department of Horticulture, University of Wisconsin for helpful comments and key editing. This program was financially supported in part by National Science Foundation in China (30730067), the State Key Basic Research and Development Plan of China (2011CB109300), Natural Science Foundation in Jiangsu Province (BK2008036), the National High-tech Program (2006AA10Z111), and the Program for 111 project (B08025).

\section{Authors' contributions}

Experiments were designed by WZG with suggestions from TZZ. WZG and HYZ conceived the experiments and analyzed the results. HYZ carried out most of the experiments and all computational analyses. Q-PCR Analysis was performed by $X Y H$. JHL, LZ, and XYX participated in part of experiments. HYZ and WZG drafted the manuscript and TZZ revised the manuscript. All authors read and approved the final manuscript.

Received: 26 October 2010 Accepted: 25 February 2011 Published: 25 February 2011

\section{References}

1. Brubaker $\mathrm{CL}$, Bourland FM, Wendel JF: The origin and domestication of cotton. In Cotton: origin, history, technology and production. Volume 1. 1 edition. Edited by: Smith WC, Cothren TJ. New York: John Wiley and Sons; 1999:3-31.

2. NCCoA: World cotton database. National Cotton Council of America; 2006 [http://www.cotton.org/econ/cropinfo/cropdata/index.cfm].

3. Stephens SG: The genetics of "Corky". The New World alleles and their possible role as an interspecific isolating mechanism. J Genet 1946, 47:150-161.

4. Chee $P$, Draye $X$, Jiang CX, Decanini L, Delmonte TA, Bredhauer R, Smith CW, Paterson AH: Molecular dissection of interspeciffic variation between Gossypium hirsutum and G. barbadense (cotton) by a backcrossself approach: I. Fiber elongation. Theor App/ Genet 2005, 111:757-763.

5. Basra AS, Malik CP: Development of the cotton fiber. Int Rev Cytol 1984, 89:65-113.

6. Shi HY, Wang XL, Li DD, Tang WK, Wang H, Xu WL, Li XB: Molecular characterization of cotton 14-3-3L gene preferentially expressed during fiber elongation. J Genet and Genomics 2007, 34:151-159.

7. Yoder MD, Keen NT, Jurnak F: New domain motif: the structure of pectate lyase c, a secreted plant virulence factor. Science 1993, 260:1503-1507.

8. Wang HH, Guo Y, LV FN, Zhu HY, Wu SJ, Jiang YJ, Li FF, Zhou BL, Guo WZ, Zhang TZ: The essential role of GhPEL gene, encoding a pectate lyase in cell wall loosening by depolymerization of the de-esterified pectin during fiber elongation in cotton. Plant Mol Biol 2010, 72:397-406.

9. Ruan YL, Llewellyn DJ, Furbank RT: Suppression of sucrose synthase gene expression represses cotton fiber cell initiation, elongation, and seed development. Plant Cell 2003, 15:952-964.

10. Ma GJ, Zhang TZ, Guo WZ: Cloning and characterization of cotton GhBG gene encoding B-glucosidase. DNA Sequence 2006, 17:355-362.

11. Pear JR, Kawagoe Y, Schreckengost WE, Delmer DP, Stalker DM: Higher plants contain homologs of the bacterial celA genes encoding the catalytic subunit of cellulose synthase. Proc Natl Acad Sci USA 1996, 93:12637-12642.

12. Li XB, Xiao YH, Luo M, Hou L, Li DM, Luo XY, Pei Y: Cloning and expression analysis of two Rac genes from cotton (Gossypium hirsutum L.). Acta Genetica Sinica 2005, 32:72-78.

13. $L i X B$, Fan $X P$, Wang $X L$, Cai $L$, Yang WC: The cotton ACTIN1 gene is functionally expressed in fibers and participates in fiber elongation. Plant Cell 2005, 17:859-875.

14. Orford SJ, Timmis JN: Specific expression of an expansin gene during elongation of cotton fibers. Biochin Biophy Acta 1998, 1398:342-346.

15. Laosinchai W, Cui X, Brown RM: A full cDNA of cotton cellulose synthase has high homology with the Arabidopsis RSW1 gene and cotton CelA1 (Accession No. AF 200453) (PGR 00-002). Plant Physiol 2000, 122:291.

16. Cui $X$, Shin $H$, Song C, Laosinchai W, Amano Y, Brown RM: A putative plant homolog of the yeast beta-1, 3-glucan synthase subunit FKS1 from cotton (Gossypium hirsutum L.) fibers. Planta 2001, 213:223-230. 
17. Gao P, Zhao PM, Wang J, Wang HY, Wu XM, Xia GX: Identification of genes preferentially expressed in cotton fibers: A possible role of calcium signaling in cotton fiber elongation. Plant Sci 2007, 173:61-69.

18. He YJ, Guo WZ, Shen XL, Zhang TZ: Molecular cloning and characterization of a cytosolic glutamine synthetase gene, a fiber strength-associated gene in cotton. Planta 2008, 228:473-483.

19. Song XL, Wang K, Guo WZ, Zhang J, Zhang TZ: A comparison of genetic maps constructed from haploid and BC1 mapping populations from the same crossing between Gossypium hirsutum L.XG. barbadense L. Genome 2005, 48:378-390.

20. Han ZG, Guo WZ, Song XL, Zhang TZ: Genetic mapping of EST-derived microsatellites from the diploid Gossypium arboreum in allotetraploid cotton. Mol Genet Genomics 2004, 272:308-327.

21. Han ZG, Wang CB, Song XL, Guo WZ, Guo JY, Li CH, Chen XY, Zhang TZ: Characteristics, development and mapping of Gossypium hirsutum derived EST-SSR in allotetraploid cotton. Theor Appl Genet 2006 112:430-439

22. Guo WZ, Cai CP, Wang CB, Han ZG, Song XL, Wang K, Niu XW, Wang C, Lu KY, Shi B, Zhang TZ: A microsatellite-based, gene-rich linkage map reveals genome structure, function, and evolution in Gossypium. Genetics 2007, 176:527-541

23. Armel S, Flagel L, Ying B, Udall JA, Wendel JF: Homoeologous nonreciprocal recombination in polyploid cotton. New Phytologist 2010, 186:123-134

24. Frelichowski JE Jr, Palmer MB, Main D, Tomkins JP, Cantrell RG, Stelly DM, Yu J, Kohel RJ, Ulloa M: Cotton genome mapping with new microsatellites from Acala 'Maxxa' BAC-ends. Mol Gen Genomics 2006, 275:479-491.

25. He DH, Lin ZX, Zhang XL, Nie YC, Guo XP, Zhang YX, Li W: QTL mapping for economic traits based on a dense genetic map of cotton with PCRbased markers using the interspecific cross of Gossypium hirsutum $\times$ Gossypium barbadense. Euphytica 2007, 153:181-197.

26. Lacape JM, Nguyen TB, Courtois B, Belot JL, Giband M, Gourlot JP, Gawryziak G, Roques S, Hau B: QTL analysis of cotton fiber quality using multiple Gossypium hirsutum $\times$ Gossypium barbadense backcross generations. Crop Sci 2005, 45:123-140.

27. Lin Z, He D, Zhang X, Nie Y, Guo X, Feng C, Stewart JM: Linkage map construction and mapping QTL for cotton fiber quality using SRAP, SSR and RAPD. Plant Breeding 2005, 124:180-187.

28. Luan M, Guo X, Zhang Y, Yao J, Chen W: QTL mapping for agronomic and fiber traits using two interspecific chromosome substitution lines of upland cotton. Plant Breding 2009, 128:671-679.

29. Qin HD, Guo WZ, Zhang YM, Zhang TZ: QTL mapping of yield and fiber traits based on a four-way cross population in Gossypium hirsutum L. Theor Appl Genet 2008, 117:883-894

30. Shen XL, Guo WZ, Zhu XF, Yuan YL, Yu JZ, Kohel RJ, Zhang TZ: Molecular mapping of QTLs for fiber qualities in three diverse lines in Upland cotton using SSR markers. Mol Breeding 2005, 15:169-181.

31. Shen XL, Zhang TZ, Guo WZ, Zhu XF, Zhang XY: Mapping fiber and yield QTLs with main, epistatic, and QTL x Environment interaction effects in recombinant inbred lines of Upland cotton. Crop Sci 2006, 46:61-66.

32. Shen XL, Guo WZ, Lu QX, Zhu XF, Yuan YL, Zhang TZ: Genetic mapping of quantitative trait loci for fiber quality and yield trait by RIL approach in Upland cotton. Euphytica 2007, 155:371-380

33. Wang BH, Guo WZ, Zhu XF, Wu YT, Huang NT, Zhang TZ: QTL mapping of fiber quality in an elite hybrid derived-RIL population of upland cotton. Euphytica 2006, 152:367-378.

34. Zhang ZS, Hu MC, Zhang J, Liu DJ, Zheng J, Zhang K, Wang W, Wan Q: Construction of a comprehensive PCR-based marker linkage map and QTL mapping for fiber quality traits in upland cotton (Gossypium hirsutum L.). Mol Breeding 2009, 24:49-61.

35. Cronn RC, Small RL, Wendel JF: Duplicated genes evolve independently following polyploid formation in cotton. Proc Natl Acad Sci USA 1999, 96:14406-14411.

36. Ruan YL, Lewellyn DJ, Furbank RT: The control of single-celled cotton fiber elongation by developmentally reversible gating of plasmadesmata and coordinated expression of sucrose and $\mathrm{K}+$ transporters and expansin. Plant Cell 2001, 13:47-60.

37. Nei M, Gu X, Sitnikova T: Evolution by the birth-and-death process in multigene families of the vertebrate immune system. Proc Natl Acad Sci USA 1997, 94:7799-7806.
38. Petrov DA, Chao YC, Stephenson EC, Hartl DL: Pseudogene evolution in Drosophila suggest high rate of DNA loss. Mol Biol Evol 1998, 15:1562-1567.

39. Force A, Lynch M, Pickett FB, Amores A, Yan YL, Postlethwait J: Preservation of duplicate genes by complementary, degenerative mutations. Genetics 1999, 151:1531-1545.

40. Blumensteil JP, Hartl DL, Lozovsky ER: Patterns of insertion and deletion in contrasting chromatin domains. Mol Biol Evol 2002, 19:2211-2225.

41. Lynch M, Conery JS: The origins of genome complexity. Science 2003, 302:1401-1404

42. Kondrashov FA, Kondrashov AS: Role of selection in fixation of gene duplications. J Theor Biol 2006, 239:141-151.

43. Lynch M, Force A: The probability of duplicate-gene preservation by subfunctionalization. Genetics 2000, 154:459-473.

44. Lynch M, O'Hely M, Walsh B, Force A: The probability of preservation of a newly arisen gene duplicate. Genetics 2001, 159:1789-1804.

45. Clark AG: Invasion and maintenance of a gene duplication. Proc Natl Acad Sci USA 1994, 91:2950-2954.

46. Walsh JB: How often do duplicated genes evolve new fuctions? Genetics 1995, 139:421-428

47. Bergthorsson U, Andersson DI, Roth JR: Ohno's dilemma: evolution of new genes under continuous selection. Proc Natl Acad Sci USA 2007, 104:17004-17009.

48. Adams KL, Cronn R, Percifield R, Wendel JF: Genes duplicated by polyploidy show unequal contributions to the transcriptome and organspecific reciprocal silencing. Proc Natl Acad Sci USA 2003, 100:4649-4654.

49. Adams KL, Percifield R, Wendel JF: Organ-specific silencing of duplicated genes in a newly synthesized cotton allotetraploid. Genetics 2004, 168:2217-2226.

50. Adams KL, Wendel JF: Allele-specific, bidirectional silencing of an alcohol dehydrogenase gene in different organs of interspecific diploid cotton hybrids. Genetics 2005, 171:2139-2142

51. Udall JA, Swanson JM, Nettleton D, Percifield RJ, Wendel JF: A nove approach for characterizing expression levels of genes duplicated by polyploidy. Genetics 2006, 173:1823-1827.

52. Samuel Yang S, Cheung F, Lee JJ, Ha M, Wei NE, Sze SH, Stelly DM, Thaxton P, Triplett B, Town CD, Jeffrey Chen Z: Accumulation of genomespecific transcripts, transcription factors and phytohormonal regulators during early stages of fiber cell development in allotetraploid cotton. Plant J 2006, 47:761-775.

53. Flagel L, Udall JA, Nettleton D, Wendel JF: Duplicate gene expression in allopolyploid Gossypium reveals two temporally distinct phases of expression evolution. BMC Biol 2008, 6:16-24.

54. Hovav R, Chaudhary B, Udall JA, Flagel L, Wendel JF: Parallel domestication, convergent evolution and duplicated gene recruitment in allopolyploid cotton. Genetics 2008, 179:1725-1733.

55. Chaudhary B, Flagel L, Stupar RM, Udall JA, Verma N, Springer NM, Wendel JF: Reciprocal silencing, transcriptional bias and functional divergence of homeologs in polyploid cotton (Gossypium). Genetics 2009, 182:503-517.

56. Raven P, Evert R, Eichhorn S: Biology of Plants New York: Worth Publishers press; 1992.

57. Endrizzi JE, Turcotte EL, Kohel RJ: Genetics, cytology, and evolution of Gossypium. Adv Genet 1985, 23:271-375.

58. Wendel JF: New world tetraploid cottons contain Old World cytoplasm. Proc Natl Acad Sci USA 1989, 86:4132-4136.

59. Zhu HY, Zhang TZ, Yang LM, Guo WZ: EST-SSR sequences revealed the relationship of D-genome in diploid and tetraploid Species in Gossypium. Plant Sci 2009, 176:397-405.

60. Rapp RA, Haigler CH, Flagel L, Hovav RH, Udall JA, Wendel JF: Gene expression in developing fibres of Upland cotton (Gossypium hirsutum L.) was massively altered by domestication. BMC Biology 2010, 8:139.

61. Voigt J, Frank R: 14-3-3 proteins are constituents of the insoluble glycoprotein framework of the chlamydomonas cell wall. Plant Cell 2003, 15:1399-1413.

62. Li H, Wu G, Ware D, Davis KR, Yang ZB: Arabidopsis Rho-related GTPases: differential gene expression in pollen and polar localization in fission yeast. Plant Physiol 1998, 118:407-417.

63. Kost B, Lemiche E, Spielhofer P, Hong Y, Tolias K, Carpenter C, Chua NH: Rac homologues and compartmentalized phosphatidylinositol 4, 52 bisphosphate act in a common pathway to regulate polar pollen tube growth. J Cell Biol 1999, 145:317-330. 
64. Molendijk AJ, Bischoff F, Rajendrakumar CSV, Friml J, Braun M, Gilroy S, Palme K: Arabidopsis thaliana Rop GTPase are localized to tips of root hairs and control polar growth. EMBO J 2001, 20:2279-2288.

65. Jones MA, Shen JJ, Fu Y, Li H, Yang ZB, Grierson CS: The Arabidopsis RopGTPase is a positive regulator of both root hair initiation and tip Growth. Plant Cell 2002, 14:763-776.

66. Delmer DP, Pear JR, Andrawis A, Stalker DM: Genes encoding small GTPbinding proteins analogous to mammalian rac are preferentially expressed in developing cotton fibers. Mol Gen Genet 1995, 248:43-51.

67. Potikha TS, Collins CC, Johnson DJ, Delmer DP, Levine A: The involvement of hydrogen peroxide in the differentiation of secondary walls in cotton fibers. Plant Physiol 1999, 119:849-858.

68. Nakanomyo I, Kost B, Chua NH, Fukuda H: Preferential and asymmetrical accumulation of a Rac small GTPase mRNA in differentiating xylem cells of Zinnia elegans. Plant Cell Physiol 2002, 43:1484-1492.

69. Kawasaki T, Henmi K, Ono E, Hatakeyama S, Iwano M, Satoh H, Shimamoto K: The small GTP-binding protein rac is a regulator of cell death in plants. Proc Natl Acad Sci USA 1999, 96:10922-10926.

70. Ono E, Wong HL, Kawasaki T, Hasegawa M, Kodama O, Shimamoto K: Essential role of the small GTPase Rac in disease resistance of rice. Proc Natl Acad Sci USA 2001, 98:759-764.

71. Li H, Shen JJ, Zheng ZL, Lin YK, Yang ZB: The Rop GTPase switch controls multiple developmental processes in Arabidopsis. Plant Physiol 2001, 126:670-684.

72. Tao LZ, Cheung AY, Wu HM: Plant Rac-like GTPases are activated by auxin and mediate auxin-responsive gene expression. Plant Cell 2002, $14: 2745-2760$.

73. Zheng ZL, Nafisi M, Arvin T, Li H, Crowell DN, Chary SN, Schroeder Jl, Shen JJ, Yang ZB: Plasma membrane-associated ROP10 small GTPase is a specific negative regulator of abscisic acid responses in Arabidopsis. Plant Cell 2002, 14:2787-2797.

74. Amor $Y$, Haigler $\mathrm{CH}$, Johnson S, Walnscott M, Delmer DP: A membraneassociated form of Sus and its potential role in synthesis of cellulose and callose in plants. Proc Natl Acad Sci USA 1995, 92:9353-9357.

75. Nolte KD, Hendrix DL, Radin JW, Koch KE: Sucrose synthase localization during initiation of seed development and trichome differentiation in cotton ovules. Plant Physiol 1995, 109:1285-1293.

76. Ruan YL, Chourey PS, Delmer DP, Perez-Grau L: The differential expression of sucrose synthase in relation to diverse patterns of carbon portioning in developing cotton seed. Plant Physiol 1997, 115:375-385.

77. Ruan YL, Chourey PS: A fiberless seed mutation in cotton is associated with lack of fiber cell initiation in ovule epidermis and alterations in sucrose synthase expression and carbon partitioning in developing seeds. Plant Physiol 1998, 118:399-406.

78. Chaudhary B, Hovav R, Flagel L, Mittler R, Wendel JF: Parallel expression evolution of oxidative stress-related genes in fiber from wild and domesticated diploid and polyploidy cotton (Gossypium). BMC Genomics 2009, 10:378.

79. Small RL, Ryburn JA, Wendel JF: Low levels of nucleotide diversity at homoelogous Adh loci in allotetraploid cotton (Gossypium L.). Mol Biol Evol 1999, 16:491-501.

80. Liu Q, Brubaker CL, Green AG, Marshall DR, Sharp PJ, Singh SP: Evolution of the FAD2-1 fatty acid desaturase 5'UTR intron and the molecular systematics of Gossypium (Malvaceae). Am J Bot 2001, 88:92-102.

81. Small RL, Wendel JF: Differential evolutionary dynamics of duplicated paralogous Adh loci in alloteraploid cotton (Gossypium). Mol Biol Evol 2002, 19:597-607.

82. An C, Saha S, Jenkins JN, Ma DP, Scheffler BE, Kohel RJ, Yu JZ, Stelly DM: Cotton (Gossypium spp.) R2R3-MYB transcription factors SNP identification, phylogenomic characterization, chromosome localization, and linkage mapping. Theor App/ Genet 2008, 116:1015-1026.

83. Cronn RC, Small RL, Haselkorn T, Wendel JF: Rapid diversification of the cotton genus (Gossypium: Malvaceae) revealed by analysis of sixteen nuclear and chloroplast gene. Am J Bot 2002, 89:707-725.

84. Drenkard E, Richter BG, Rozen S, Stutius LM, Angell NA, Mindrinos M, Cho RJ, Oefner PJ, Davis RW, Ausubel FM: A simple procedure for the analysis of single nucleotide polymorphisms facilitates Map-Based Cloning in Arabidopsis. Plant Physiol 2000, 124:1483-1492.

85. Van-Ooijen JW, Vorrips RE: JoinMapR Version 3.0: Software for the Calculation of Genetic Linkage Maps. CPRO-DLO, Wageningen; 2001.
86. Hurst LD: The Ka/Ks ratio: diagnosing the form of sequence evolution. TRENDS in Genetics 2002, 91:8486-487.

87. Jiang JX, Zhang TZ: Extraction of total RNA in cotton tissues with CTABacidic phenolic method. Cotton Sci 2003, 15:166-167.

doi:10.1186/1471-2229-11-40

Cite this article as: Zhu et al:: Structure, expression differentiation and evolution of duplicated fiber developmental genes in Gossypium barbadense and G. hirsutum. BMC Plant Biology 2011 11:40.

\section{Submit your next manuscript to BioMed Central and take full advantage of:}

- Convenient online submission

- Thorough peer review

- No space constraints or color figure charges

- Immediate publication on acceptance

- Inclusion in PubMed, CAS, Scopus and Google Scholar

- Research which is freely available for redistribution

Submit your manuscript at www.biomedcentral.com/submit
Biomed Central 